Revista de Estudios Histórico-Jurídicos

[Sección historia de los derechos patrios iberoamericanos]

XLII (Valparaíso, Chile, 2020)

[pp. 455-473]

\title{
Mariano H. Cornejo y el Proyecto de Jurado en la JUSTICIA PENAL PERUANA DEL SIGLO XX
}

[Mariano H. Cornejo and the jury project in the peruvian criminal justice of the 20th century]

\author{
José Luis Rivera Villanueva* \\ Universidad Nacional Mayor de San Marcos, Perú
}

\begin{abstract}
RESUMEN
Mariano Hilario Cornejo no fue un jurista. Fue un sociólogo proveniente, principalmente, del positivismo francés. Esta particularidad permite identificar un singular aborde de la justicia penal, bajo la vigencia de un discurso que, si bien no se ajusta al tradicional discurso jurídico procesal, sí resulta bastante claro y sistemático, hasta el punto de haberse concretado en el Código de Procedimientos en Materia Criminal de 1920 cuyo mérito, a diferencia de los demás movimientos de reforma procesal penal en el Perú, fue marcar un antes y un después en lo concerniente a la separación de las funciones de investigación y juicio que, de hecho, las siguientes reformas mantendrían. Así, en apretada síntesis, el cambio gravitacional de la reforma en materia de justicia penal en el Perú no se debió a la influencia de los juristas, sino al pensamiento sociológico. Desde esta perspectiva, en el presente artículo se advertirá como el pensamiento de D. Mariano Hilario Cornejo fue una constante en su desarrollo, como académico y político, a partir de la noción central del "equilibrio de poderes" y de "paridad entre los mecanismos de poder y de control", que, en el ámbito de la justicia penal, le permita fundamentar la necesidad de implementar un sistema de jurado en el Perú de inicios del siglo XX.
\end{abstract}

Abstract

Mariano Hilario Cornejo was not a jurist. He was a sociologist mainly influenced by the French positivism, feature which allows identifying the unique way in which he addressed criminal justice, under a discourse that, albeit is not in line with the traditional juridical-procedural discourse, it was quite clear and systematic. This was so up to the point that his ideas were implemented by the Criminal Code of 1920, merit of which, unlike the other Peruvian movements for Criminal Procedure Reform, was to establish a turning point regarding the separation of the investigative and trial functions, which indeed was to be maintained by the subsequent reforms. Thus, in a nutshell, the gravitational change of the reform in terms of criminal justice in Peru took place due to the sociological thinking rather than due to the jurists' influence. From this approach, in this article, Mr. Mariano Hilario Cornejo's thought is examined and recognized as a constant factor in his pathway as professor and politician, based on the central concepts of "balance of powers" and "balance between the power and control mechanisms", which, in the criminal justice scope, allowed him to provide the grounds for the need to implement a jury system in Peru at the turn of the 20th century.

* Abogado por la Universidad Nacional Mayor de San Marcos. Maestrando en Ciencias Penales por la Universidad Nacional Mayor de San Marcos. Miembro del Instituto de Ciencia Procesal Penal - Perú. Correo electrónico: riveravillanueva.jose@gmail.com 
Palabras clave

Positivismo - Patria nueva - jurado.
KEY WORDS

Positivism - Patria nueva - jury.

ReCibIDO el 24 de enero de 2020 y ACEPTADO el 13 de julio de 2020

\section{INTRODUCCIÓN}

El positivismo fue una corriente filosófica que provino de las ciencias naturales. Desde ahí influyó en diversos ámbitos del conocimiento, incluso en el estudio de los fenómenos sociales ${ }^{1}$. Dicha influencia se debió a la necesidad de alcanzar una fórmula general que explique todos los fenómenos a partir de un común denominador, construido de manera sistemática y basada en la razón humana, en oposición a todo indicio de divinidad propia del medioevo.

Desde el punto de vista político, el positivismo coincidió con el surgimiento de una nueva clase social, cuyos criterios y modos de vida necesitaban una explicación coherente con sus propias pretensiones.

El positivismo se convirtió en una corriente ideológica dominante en Francia en la segunda mitad del siglo XIX, bajo la influencia de Augusto Comte (17961857). A partir de ahí, dicho pensamiento tuvo una seria repercusión en el Derecho, que no tardaría de manifestarse en Latinoamérica, a fines del siglo XIX y comienzos del siglo $\mathrm{XX}^{2}$.

Una primera idea se puede extraer de todo ello: los discursos que han de producirse en dicha época, y que mayor influencia tendrán en el Perú en lo penal, serían aquellos que, de alguna u otra forma, han bebido del positivismo ${ }^{3}$, aunque, evidentemente, dicho pensamiento no fue el único vigente en la época ${ }^{4}$.

Este es el contexto en que se desenvolvió Mariano Hilario Cornejo Zenteno, sobre el cual nos centraremos en lo sucesivo.

La importancia de su estudio radica en su sólida formación en el campo sociológico, lo que acarreó lo siguiente: i) la creación de la primera cátedra de Sociología en la Facultad de Letras de la Universidad Nacional Mayor de San Marcos en

\footnotetext{
${ }^{1}$ Aguirre, Carlos, Delito, raza y cultura: El desarrollo de la criminología en el Perú (18901930), en Diálogos en Historia, 2 (2000), p. 180.

${ }^{2}$ Peralta, Víctor. Un científico en la política peruana. Mariano H. Cornejo, la república aristocrática y la patria nueva, 1895-1920, en Revista Complutense de Historia de América, 27 (2001), p. 163.

${ }^{3}$ Aguirre explica en los siguientes términos: "Hacia fines de la década de los 80 del siglo XIX la criminología, la nueva ciencia del delito, llegó al Perú, y con ella la promesa de ofrecer explicaciones científicas del delito y de proponer políticas eficaces para su control. Al igual que sus colegas europeos, los expertos peruanos se enfrascaron en discusiones en torno a las explicaciones científicas de las conductas delictivas. La importancia relativa de los factores sociales y biológicos para explicar las tendencias criminales fue un tema de intensa polémica". Aguirre, Carlos, cit. (n. 1), p. 180.

${ }^{4} \mathrm{El}$ desarrollo de la sociedad peruana a comienzos del siglo XX significó, a su vez, la resistencia procedente de las corrientes filosóficas tradicionales, como el espiritualismo de Deustua, o de nuevos discursos como el indigenismo de Castro Pozo; a la vez que propició el contexto idóneo para el surgimiento -todavía prematuro- de corrientes de pensamiento que marcarían el siglo XX en la historia del Perú: El socialismo de José Carlos Mariátegui y el aprismo de Víctor Raúl Haya de la Torre.
} 
1896. Dicha iniciativa fue bastante moderna en el contexto latinoamericano, si se tiene en cuenta que la primera cátedra de Sociología recién fue fundada el año 1887 en Francia, por Emile Durkheim (1858-1917); a la vez que en Inglaterra, dicha cátedra recién vio la luz el año $1906^{5}$; ii) la publicación en Madrid de su obra-Tratado de Sociología General-compuesta en dos volúmenes, cuya difusión irradió América Latina, a la vez que influenció en la academia francesa, luego de su traducción al idioma francés el año 1930, y su publicación con el prólogo de René Worms. A decir de Rochabrún, si bien "Nadie hoy en día lee a Cornejo, [...] es difícil encontrar otra obra de un latinoamericano que en esa época, y en un campo ajeno a la literatura, haya tenido en Europa -amén de América Latinauna acogida similar"'.

La a p a r e n te contradicción sobre la cual se centrará la reflexión final en relación al pensamiento de Cornejo radica en explicar cómo es que un teórico de su talla, con una marcada influencia del positivismo evolucionista de Comte y Spencer ${ }^{7}$, o, en términos de Mejía Navarrete, un sociólogo especulativo antes que empírico ${ }^{8}$, terminó fundamentando la implementación de un sistema de jurado abiertamente contrario al sistema de jueces técnicos, cuya vigencia en el Perú tuvo un gran respaldo por los principales representantes provenientes del campo jurídico. Con este objeto, abundaremos en su vida, el contexto en que se desenvolvió y su pensamiento, a efecto de realizar, al término, un balance integral.

\section{VIDA}

Mariano Hilario Cornejo Zenteno nació el 29 de octubre de 1866 en Arequipa. Fue hijo de Mariano Lino Cornejo, de familia arequipeña venida de Tacna y emigrada de Argentina; abogado, coronel y político, que fue ministro del Perú en Bolivia y amigo personal del General Mariano I. Prado; y de doña Dorlisca Zenteno, nieta de D. Domingo Infantas, tacneño, general peruano que acompañó al General Santa Cruz en su campaña por la Confederación Perú-Boliviana y,

\footnotetext{
${ }^{5}$ Rochabrún Silva, Gillermo, Sociología y pensamiento social en el Perú 1896-1970. Encuentros y desencuentros (Tesis para optar el grado académico de Magister en Sociología, Lima, 1998), p. 1. En el mismo sentido, Sulmont, Denis, La sociología francesa en el Perú, en Bulletin de l'Institut Français d'Études Andines, 36/1 (2007), p. 86. Esta situación coincidió con una serie de iniciativas del gobierno, destinadas a afianzar sus relaciones diplomáticas con Francia, a la vez que Chile hacía lo propio con Inglaterra y Alemania (Rochabrún Silva, Guillermo, esta nota, p. 12). Dentro de este contexto, la academia no podía mantenerse ajena. Así las cosas, es razonable que Mariano $\mathrm{H}$. Cornejo, y otros pensadores de su generación, hayan sido influenciados por la escuela francesa, hasta el punto de publicar sus obras en idioma francés y no en español. Este es el caso, por ejemplo, de Francisco García-Calderón, cuya obra Le Perou Contemporain fue publicada originalmente en francés el año 1907, en París, por la editorial Dujarric et Cie. Dicha obra, anecdóticamente, recién sería publicada en español el año 1981.

${ }^{6}$ Rochabrún SILVA, Guillermo, cit. (n. 6), p. 1.

${ }^{7}$ Sulmont, Denis, cit. (n. 6), p. 86.

${ }^{8}$ MejÍA Navarrete, Julio, El desarrollo de la sociología en el Perú. Notas introductorias, en Sociologias, 14/7 (Porto Alegre, 2005), p. 308.
} 
luego de la derrota en Yungay, se retiró de la política para dedicarse a la minería en su hacienda de San Juan de Dios, en Puno?.

Su formación primaria y secundaria la realizó en Puno, concluyéndola en el Colegio de San Carlos. Cursó sus estudios superiores en la Universidad Nacional de San Agustín de Arequipa (1884-1886) y los continuó en la Universidad Nacional Mayor de San Marcos, en Lima.

En esta última Casa de Estudios obtuvo los grados de bachiller y doctor en Letras, con la defensa de las tesis El progreso indefinido (1886) y Sociología del arte (1887). También se graduó de bachiller en Jurisprudencia, con la defensa de la tesis El sistema hipotecario que nos rige es una institución defectuosa de nuestro derecho civil (1887). Posteriormente, se graduó de bachiller y doctor en Ciencias Políticas y Administrativas, con la defensa de la tesis Las ventajas del jurado y El Gobierno parlamentario (1896).

Estos trabajos realizados para obtener sus grados académicos permitieron advertir que el pensamiento de Cornejo tuvo un enfoque interdisciplinario, prematuro para la época, entre la Sociología y el Derecho, habida cuenta de que, en el contexto peruano, el campo del Derecho estuvo acompañado de "[...] un excesivo ritualismo jurídico en la vida social y política [...]"10. Asimismo, dicho desenvolvimiento intelectual sentaría las bases de su obra cumbre: Tratado de Sociología General, publicado en Madrid, durante los años 1908 y 1910, y publicada en francés en la década de los treinta.

Mariano H. Cornejo falleció a los 76 años de edad en Francia, el 25 de marzo de 1942, después de permanecer 22 años en dicho país, desde el primero de mayo de $1920^{11}$.

\section{COYUNTURA POLÍTICA, ECONÓMICA Y SOCIAL}

No se puede entender el pensamiento de Mariano H. Cornejo si, previamente, no se da cuenta del contexto que lo rodeó. A lo largo de sus 76 años de edad, la sociedad peruana y el modo de gobierno cambiaron radicalmente.

Su nacimiento y primeros años de vida estuvieron acompañados de una aguda crisis caudillista en torno al gobierno peruano ${ }^{12} \mathrm{y}$ una incipiente formación de lo que sería el primer partido político: el Partido Civil (1871), con una fuerte

${ }^{9}$ Cornejo, Ricardo H., Datos biográficos y remembranzas, en Cornejo, Ricardo H., Mariano H. Cornejo. Discursos escogidos y datos biográficos (Lima, Editorial Jurídica SA, 1974), p. 6.

${ }^{10}$ Rochabrún Silva, Guillermo, cit. (n. 6), p. 3.

${ }^{11}$ A decir de Ricardo Cornejo, desde 1920, Mariano H. Cornejo viajó hasta en tres breves ocasiones a Perú entre 1920 y 1942, “[...]siempre para desvanecer intrigas malévolas (en una ocasión yo mismo tuve que enfrentarlas). También viajó a Lima en 1934 y en 1936 por asuntos personales". CoRnejo, Ricardo H. , cit. (n. 10), p. 10.

${ }^{12} \mathrm{Un}$ año antes de su nacimiento, en 1865 , se produjo la Guerra Civil cuyo epicentro fue Arequipa y que tuvo como resultado la deposición de Pezet y el establecimiento de una dictadura patriótica bajo el liderazgo del coronel Prado. Quiroz resume este pasaje en los siguientes términos: "En alianza con Chile, el Perú le declaró entonces la guerra a España. Pezet fue acusado de tiranía, traición y robo de fondos públicos, cargos a los que respondió indicando que los grandes gastos y préstamos a alto interés eran urgentemente necesarios para 
presencia de la oligarquía limeña. Esta situación, evidentemente, sería más crónica con ocasión de la Guerra del Pacífico (1879-1884).

La juventud y madurez de Cornejo se desarrolló en un contexto de progresivo desarrollo desde el punto de vista económico y social, si bien con ciertos momentos de crisis en el ámbito político. Este periodo se produjo bajo la dirección del partido demócrata de Piérola y una serie de gobiernos secundados por el Partido Civil, cuyos ideólogos, a decir de Rochabrún Silva, "[...] sintieron la necesidad de repensar el país sobre nuevas bases, distanciándose culturalmente de los grupos gobernantes, aunque sin romper con ellos y sin poder identificarse con el pueblo"13.

El actuar de Cornejo, de hecho, fue un vivo reflejo de dicha situación, toda vez que sus intervenciones políticas siempre tuvieron como fin mantener la cohesión de los partidos políticos formados por civiles frente a cualquier indicio que podría significar el rebrote militar.

Esta situación también tiene correspondencia en la política, cuyos gobiernos, entre 1884 a 1930, oscilaron sucesivamente desde una fuerte presencia militar, a través del Partido Constitucional del General Andrés Avelino Cáceres (18331823), hacia la preeminencia de los civiles en el poder, a través del Partido Demócrata y el Partido Civil. El año 1930, finalmente, sería testigo del retorno de las fuerzas armadas al gobierno, luego del golpe de Estado propiciado contra el régimen de Leguía por el comandante Luis Miguel Sánchez Cerro (1889-1933), en beneficio del Partido Civil relegado por aquel gobierno.

Nótese que, para este periodo, la ideología militar y civil fue de un extremo a otro, en el sentido de que mientras el gobierno militar del siglo XIX apostó por resolver los problemas sociales a través de la reducción del Estado a su mínima expresión $^{14}$; los gobiernos civiles tendieron a un robustecimiento progresivo del Estado, cuya máxima expresión fue, precisamente, el Oncenio de Leguía.

En este periodo, Mariano H. Cornejo, en su faceta de político, se caracterizó por formar parte de los partidos Demócrata (Piérola y Billingurst) y Civil (Leguía), situación que no fue gratuita. Y es que ello sirvió de argumento a Miró Quesada Laos para tildarlo de "conspirador y oportunista político" 15 , habida cuenta,

la defensa nacional". Quiroz, Alfonso W., Historia de la corrupción en el Perú (Lima, Instituto de Estudios Peruanos, 2013), p. 158.

${ }^{13}$ Rochabrún SILVA, Guillermo, cit. (n. 6), p. 10.

${ }^{14} \mathrm{Al}$ respecto, Contreras y Zuloaga resumen este primer periodo en los siguientes términos: "Incapaz de sostener una numerosa burocracia, el tamaño del Estado se redujo a su mínima expresión. Su presencia en las provincias se limitaba al funcionamiento de la autoridad delegada por el poder central (prefectos en los departamentos y subprefectos en las provincias) apoyada por unas docenas de policías. Las autoridades del interior casi siempre eran militares. De un lado, porque así el Estado podía ahorrarse un sueldo; de otro, porque se trataba del patrón ordinario desde la independencia: los militares hacían la guerra en tiempos de convulsión y se dedicaban al gobierno en las épocas de paz. Para cobrar sus salarios, los policías y subprefectos no podían esperar, como antes, las remesas del gobierno central, por lo que, fusil en mano, salían a cobrar las contribuciones fiscales a los campesinos y comerciantes". Contreras, Carlos, \& Zuloaga, Marina, Historia minima del Perú (Madrid, Turner Publicaciones, 2019), p. 205.

${ }^{15}$ Miró Quesada Laos, Carlos, Autopsia de los partidos políticos (Lima, Ediciones Páginas 
continúa dicho autor, de su trayectoria política, muchas veces simultáneamente, como demócrata, pierolista, pardista, billinghurista y leguiísta ${ }^{16}$.

Evidentemente, lo sostenido por Miró Quesada Laos podría ser de recibo si es que se abordase el pensamiento de Mariano H. Cornejo desde un punto de vista partidista. Sin embargo, dicha lectura no sería justa. Y es que, a partir de sus intervenciones políticas, se tiene que la actuación de Mariano H. Cornejo no respondía a una lógica partidista, sino de la preservación de lo que él entendía como bi e n comú n, es decir de la defensa del equilibrio existente entre la libertad individual y el orden, inseparables en la política, hasta el punto de que no podían contraponerse ni en lo abstracto ni en lo real ${ }^{17}$. Por ejemplo, ello se puede advertir en dos oportunidades.

Primero, en su decisión de criticar al partido aliado del Partido Demócrata, el Partido Civil ${ }^{18}$, cuando este, en lugar de continuar con el desarrollo de la r e p úblic a té c n i c a de Piérola, se dejó influenciar por intereses partidistas encubiertos bajo la intensión de plasmar la r e p ú b l i c a p rá c t i c a formulada en 1870 por Manuel Pardo (1834-1878).

Basadre resume magistralmente este pasaje en los siguientes términos: “[...] Por la transacción de Piérola con los civilistas, fue elegido, de común acuerdo y después de muchos conciliábulos, don Eduardo López de Romaña. Hubo falta de acierto en la elección de este hombre; y ello con el abandono que Piérola hizo con cívica abnegación de su influencia palaciega apenas dejó de ser presidente, acentuó la ligazón mayor del civilismo al poder, y, más tarde, la marcha de los demócratas a la oposición. Tal como estaba constituida la Junta Electoral Nacional, el gobierno mandaba en ella y al gobierno lo manejaban los civilistas. Piérola era un caudillo con entusiastas y heterogéneos adeptos, como ningún caudillo de otrora; pero el civilismo era una casta. Estando en el gobierno esta casta y siendo ella formada por los propietarios urbanos y rústicos, los contribuyentes de eficaz acción en las elecciones, lógicamente resultaban civilistas. Además, el voto era público y en consecuencia los ricos podían comprarlo. Piérola se había puesto la soga al cuello con la ley de 1896. Los medios legales le quedaron vedados para regresar al gobierno. Fue así cómo se retiró de la lucha en 1903 ante la elección de Candamo, en 1904 ante la elección de Pardo, en 1908 ante la elección de Leguía. Ni siquiera alcalde de Lima pudo ser el hombre que había iniciado la modernización de la capital y que la había hecho progresar como nadie"19.

Si bien lo señalado difiere de lo sostenido por Peralta, para quien la denuncia de Mariano H. Cornejo al Partido Civil se debió a que este haya decidido pactar

Peruanas, 1961), p. 454.

${ }^{16}$ Ibíd.

${ }^{17}$ Cornejo, Mariano Hilario, Discurso pronunciado el 13 de agosto de 1901 en defensa de los fueros del parlamento al sostener el voto de censura al gabinete Almenara, en CORNEJO, Ricardo H., Mariano H. Cornejo. Discursos Escogidos (Lima, Editorial Jurídica, 1974), p. 124.

${ }^{18} \mathrm{La}$ alianza entre el Partido Demócrata y el Partido Civil se remonta a fines del siglo XIX (1894), circunstancia en que se da origen a la Coalición Nacional para hacer frente al Partido Constitucional. Basadre Grohmann, Jorge, Perú: Problema y posibilidad (Lima, Librería Francesa Científica y Casa Editorial E. Rosay, 1931), pp. 143-145.

${ }^{19}$ Ibíd., pp. 149-150. 
con el Partido Constitucional para participar en las elecciones presidenciales de $1903^{20}$; lo cierto es que, en cualquiera de ambas interpretaciones, la decisión de Mariano H. Cornejo de criticar al Partido Civil puede deberse al desequilibrio que aquel advirtió entre la libertad individual y el orden, toda vez que las acciones adoptadas por el Partido Civil no apuntaron a preservar el bien común ${ }^{21}$, sino a diseñar el mejor modo de mantenerse en el Poder Ejecutivo y, desde ahí, influir en los demás poderes del Estado.

Siguiendo esta línea, luego se entendería cómo es que el pensamiento de Cornejo podría ser afín para Leguía, quien estando en el poder procuró refundar el Perú a través de la implementación de su denominada Patria $\mathrm{Nueva}$, con una manifiesta intención de reducir la influencia de su partido de origen: el Partido Civil.

La segunda oportunidad en que Mariano H. Cornejo decidió seguir sus ideales en aras del b i e n co m ú $\mathrm{n}$, antes que actuar de acuerdo al Partido Demócrata del que provenía, comprendió su alianza con la facción progresista del Partido Civil liderada por Augusto B. Leguía (1863-1932), al advertir la inestabilidad propiciada como consecuencia de la pugna entre dos sectores del Partido Civil: el sector progresista liderado por José Pardo y Barreda (1864-1947) y el sector conservador liderado por Mariano Prado y Ugarteche ${ }^{22}$, sumado al retiro definitivo de Piérola y del Partido Demócrata de la vida política ${ }^{23}$.

Así las cosas, sería precisamente en el gobierno de Augusto B. Leguía que Mariano H. Cornejo, un político con trayectoria en el parlamento, y con esporádicos autoexilios, encontraría el espacio ideal para impulsar su concepción sobre el jurado en la vida política.

Por todo ello, coincidimos con Peralta al sostener que Cornejo no fue ningún oportunista ni un improvisado en la política; por el contrario, esta fue subordinada a su ideología positivista, a la vez que fueron los propios líderes políticos los que buscaron a Cornejo para argumentar sus actos públicos, como ocurrió con los presidentes Bilinghurst y Leguía. Sin embargo, conviene reconocer también que dicha concepción, atractiva para los líderes políticos, importó la desestabilización del sistema político de la República Aristocrática a través de la fundamentación doctrinaria de la Patria Nueva, a la vez que dicha fundamentación le acarrearía un alto costo, al marginar a la oposición a través de lo que entendía como la

${ }^{20}$ Peralta, Víctor, cit. (n. 3), pp. 173-174. Este suceso no fue un hecho aislado. La alianza entre el Partido Civil y Cáceres, del Partido Constitucional, es reseñada por Quiroz, quien sostiene que "Según un diplomático francés que recordaba las 'exacciones' cometidas durante el anterior régimen de Cáceres, [el presidente civilista] López de Romaña se habría rodeado imprudentemente de caceristas a los cuales otorgó puestos militares importantes para contrarrestar a Piérola”. Quiroz, Alfonso W., cit. (n. 13), p. 217. Lo propio se aprecia con ocasión de una generosa recompensa concedida por José Pardo a favor de Cáceres por el respaldo prestado en una representación diplomática plenipotenciaria en Roma. Ibíd.

${ }^{21}$ A decir de Mariano H. Cornejo, la sociedad constituye un organismo vivo con dos fuerzas internas, cuya evolución del equilibrio social dependerá de cómo dichas fuerzas se vigorizan o se extravían. Dicho e q u i 1 i b r i o es el b i e n c o m ú n. Peralta, Víctor, cit. (n. 2), p. 167.

${ }^{22}$ Peralta, Víctor, cit. (n. 2), pp. 174-175.

${ }^{23}$ Basadre Grohmann, Jorge, cit. (n. 19), pp. 154-156, 173. 
d e m o c r a c i a e fe c t i v a, del cual se sirvió Leguía para implantar un sistema dictatorial ${ }^{24}$.

En cuanto al ámbito económico y social, el Perú de la época de Mariano H. Cornejo adolece de una abismal brecha social. Esta situación permitió visibilizar ciertos problemas que no habían sido objeto de preocupación en los gobiernos pretéritos ni en la academia, principalmente de corte biologicista, tales como la relacionada al indígena, al concepto de nación, a la necesidad de diversificar la economía, entre otros. Todo ello, evidentemente, llevó a la clase dirigente a dejar sus polémicas dogmáticas a cambio de intentar dar respuesta a un problema pragmático, relacionado con la capacidad del Estado para imponer efectivamente su autoridad en todo el territorio nacional, frente a poderes regionales que, incluso, podían rivalizar con el Ejército oficial, a través del mantenimiento de ejércitos privados -las montoneras ${ }^{25}$.

Así las cosas, el presente periodo -principalmente la década de los veinte del siglo XX- se caracterizó por una marcada especialización de las fuerzas armadas, el fortalecimiento de una política diplomática que concluyó con la delimitación definitiva de cuatro de las cinco fronteras con los países vecinos (Chile, Bolivia, Brasil y Colombia), la recuperación de Tacna, y la modernización de las ciudades que, a su vez, implicó el surgimiento de una nueva clase social: el proletariado. Este escenario permitió, la proliferación del pensamiento positivista, toda vez que esta, basada en una noción de o r d e n y p r o g r e so, permitió explicar la realidad nacional como un estadio superior - e v o l u c i o n a d o - frente a lo pasado.

Así, mientras Ricardo Palma -influenciado por el darwinismo social-, entiende que "[...] el gran problema era el enorme peso que la población indígena tenía sobre el conjunto del país", hasta el punto de considerar que la causa de la derrota de 1879 ante Chile fueron ellos, toda vez que "Los países indios estaban condenados a perder las guerras ante los países blancos [...]"; el gobierno de Morales Bermúdez adoptó ciertas políticas públicas tendientes a "[...] atraer a inmigrantes de raza blanca" ${ }^{26}$. De ahí que, por ejemplo, Morales Bermúdez, en 1893, haya concedido "[...] importantes facilidades a los promotores de la inmigración y a los mismos colonos: viaje gratuito hasta el Perú, una semana de alojamiento en Lima cubierta por el gobierno, traslado gratuito hasta el lugar de instalación definitiva, semillas, tierras y animales sin costo y exoneración fiscal por cinco años" 27 . Y, sin embargo, concluyen los autores, los inmigrantes nunca se asomaron, lo que fue interpretado por los promotores como el resultado de los

${ }^{24}$ Peralta, Víctor, cit. (n. 2), pp. 188-189.

${ }^{25}$ Rochabrún Silva, Guillermo, cit. (n. 6), p. 14.

${ }^{26}$ Es preciso indicar que este hecho formó parte de una política iniciada muchos años atrás, si bien no con la frecuencia que se esperaba. Así, puede advertirse que ya Ramón Castilla había tomado una idéntica decisión, al impulsar la migración de los alemanes, tal y como fue registrado por la Sociedad Central de Emigración Alemana el año 1851. Para mayor referencia, ver Sociedad Central de Emigración Alemana, Emigración alemana con destino al Perú año de 1851 (Londres, T. E. Newell S. Cloak Lane, Cheapsdk, 1855).

${ }^{27}$ Contreras, Carlos, \& Zuloaga, Marina, cit. (n. 15), pp. 207-208. 
terratenientes, cuyo interés siempre fue acaparar las tierras agrícolas, e impedir el arribo de inmigrantes ${ }^{28}$.

En la academia, el positivismo también estuvo secundado por otros autores, principalmente provenientes de la clase social aristocrática. Estos son, entre otros, Javier Prado (1871-1921), Manuel Vicente Villarán (1873-1958), Luis Miró Quesada (1880-1976), Francisco García Calderón (1883-1953), Víctor Andrés Belaunde (1883-1966) y José de la Riva Agüero (1885-1944) ${ }^{29}$.

Evidentemente, esta línea de interpretación encontró su contrapeso en los primeros años del siglo XX, caracterizado por el surgimiento de una corriente indigenista con base, también, en el positivismo.

Uno de los exponentes en esta materia fue Hildebrando Castro Pozo, quien en 1919 defendió su tesis El problema sociológico legal de las comunidades indígenas para obtener el grado de bachiller en Jurisprudencia en la Universidad Nacional Mayor de San Marcos, a la vez que, en el ámbito político, el gobierno de turno dispuso la creación de un nuevo ministerio: el ministerio del trabajo y de asuntos indígenas. Ramos Rau indica que el enfoque de Castro Pozo no fue único, advirtiéndose toda una corriente de opinión en esa línea, liderada, entre otros, por José Antonio Encinas, Abelardo Solís, Erasmo Roca, Carlos Doig y Lora y Juan Manuel Carreño ${ }^{30}$.

En este escenario, Mariano H. Cornejo, paradójicamente, no emitió alguna opinión particular sobre lo "indígena como problema social", lo que llama la atención porque "[...] Cornejo había vivido en su niñez en una hacienda de Puno y fue diputado y senador por ese departamento" ${ }^{31}$.

Esta situación, a decir de Mejía Navarrete, se explicaría toda vez que "Nuestros catedráticos [llegaron] a ser sociólogos de manera episódica, sólo cuando enseñan en la universidad, su formación y vocación no es la Sociología, [en tanto que] no están interesados en estudiar la realidad nacional. Cornejo es abogado, diplomático y político parlamentario. Wiesse destacó en la diplomacia y el periodismo. Mac Lean es abogado, político y parlamentario" ${ }^{32}$. Por lo tanto, sentencia Mejía Navarrete, "La Sociología [fue] una preocupación y actividad secundaria, como lo es en el pensamiento social peruano"33, situación que, en términos contemporáneos, recién se intensifica en la segunda mitad del siglo XX.

Sin embargo, en el pensamiento de Cornejo sí puede rescatarse un decidido divorcio de aquellos discursos que buscaban legitimar ciertas clases sociales a partir de d e f e c t o s atribuidos a los indios, tal y como lo sostuvo en su conferencia de 1916 pronunciada en el Cine Excelsior, en los siguientes términos: "En el Perú, los hombres son como en todas partes, hay virtudes y apetitos, hay abnegaciones ejemplares y vulgares arribistas: solamente que por la imperfección del medio

\footnotetext{
${ }^{28}$ Ibíd., p. 208.

${ }^{29}$ Rochabrún Silva, Guillermo, cit. (n. 6), p. 11.

${ }^{30}$ Ramos Rau, Demetrio, Hildebrando Castro Pozo, en Pueblo Continente, $17 / 1$ (2006), p. 98.

${ }^{31}$ Rochabrún Silva, Guillermo, cit. (n. 6), p. 4.

${ }^{32}$ Mejía Navarrete, Julio, cit. (n. 9), p. 308.

${ }^{33}$ Ibíd.
} 
social, la selección invertida dificulta o esteriliza la obra del bien y abre la intriga ancho el camino de todos los éxitos y de todas las posiciones [sic])"34.

\section{Mariano H. Cornejo y la "Patria Nueva"}

Las dos oportunidades en que Augusto B. Leguía asumió el poder coincidieron con dos momentos en que Mariano H. Cornejo alcanzó gran notoriedad, tanto en el ámbito académico como político.

Así, mientras durante el primer gobierno de Leguía (1908-1912) Cornejo publicaba su Tratado de Sociología general en Madrid (1908 y 1910); durante el segundo gobierno de aquel, entre 1919 a 1930, se produjo la entrada en vigencia del Código de Procedimientos en Materia Criminal aprobado el 2 de enero de 1919 y la aprobación de la Constitución Política el 18 de enero de 1920, inspirados en el pensamiento de Cornejo.

Ello permite advertir que la madurez intelectual de Mariano H. Cornejo coincidió con el establecimiento de la "Patria Nueva", hasta el punto de ser uno de los ideólogos más influyentes. Pero, ¿cómo es que un militante demócrata reformista como Mariano H. Cornejo, ex simpatizante de Piérola, alcanzó tal influencia al interior de un gobierno civil que, de hecho, había resuelto desestabilizar el statu quo vigente hasta dicha época?

Para entenderlo es preciso identificar la coyuntura de 1919. A decir de Guerra Martiniére, "Las elecciones convocadas por Pardo para este año nos enfrentan con una situación sumamente difícil, pues los partidos políticos existentes, excepto el Civil en cierta forma y el Liberal por su tradición, eran partidos que habían girado en torno a una figura que para entonces ya había caducado, tales los casos del partido Demócrata, cuyo caudillo había muerto en 1913, y el Constitucional, liderado por el general Cáceres, quien era respetado como héroe de la guerra con Chile, pero no representaba un pensamiento político definido. El partido Liberal era minoritario y correspondía al patrón político que cerraba el siglo anterior. El partido Civil, entonces en el gobierno, se había resquebrajado internamente y se había desprestigiado en la detentación del poder, tanto legislativo como ejecutivo, en forma casi ininterrumpida desde principios del siglo, además, al igual que el anterior, mantenía los ideales que habían tenido vigencia en la pasada centuria" 35 .

Esta situación, evidentemente, fue aprovechada por Leguía quien, al destacarse por ser un " $[. .$.$] hombre práctico, no doctrinario, con mentalidad empresarial$ manejada políticamente [...]"36, supo dirigir la situación hasta el punto de ganarse a la población con discursos marcadamente populistas, tales como el pronunciado el 9 de febrero de 1919 en el Club de La Unión: "Se os ha pretendido exhibir como un pueblo desprovisto de patriotismo y en decadencia, pero aquí estoy

\footnotetext{
${ }^{34}$ Cornejo, Mariano Hilario, Conferencia sobre el Jurado sustentada por el Presidente de la Comisión Reformadora de los Códigos Penales, Dr. D. Mariano H. Cornejo, el domingo 6 de agosto de 1916, en el Teatro Excélsior (Lima, Imprenta del Estado-Núñez, 1916), p. 8.

${ }^{35}$ Guerra Martiniére, Margarita, La "Patria nueva" de Leguía, en Boletín del Instituto Riva-Agüero, 16 (1989), p. 245.

${ }^{36}$ Ibíd.
} 
yo para trabajar incansablemente hasta demostrar no solo a la América, sino al mundo entero que el Perú es un pueblo de patriotas, y trataré de dar solución a los grandes problemas nacionales, tanto internos como externos, sin menoscabo de la dignidad del país, y haré que se reconozca el derecho y la justicia que nos asiste para reclamar lo que en días de decadencia nacional se nos arrebató" ${ }^{37}$.

Así las cosas, la confluencia del ímpetu empírico de Leguía y el intelecto de Cornejo le permitió a aquel formar las bases propias de su plan de gobierno, evidentemente, en lo que le fuere conveniente.

Es preciso citar el siguiente fragmento de su programa escrito en 1920, en el cual se puede apreciar la viva pluma de Cornejo: "[El establecimiento del partido es ideal para la] Defensa de los intereses nacionales, por una legislación que, sin desconocer el ejercicio de las garantías individuales y sociales, asegure el predominio del orden público, desarrollo cultural y material, por la asistencia social y por la protección a la raza indígena, por la dación de leyes para el mejoramiento y adelanto de las clases obreras y para garantizar la armonía entre el capital y el trabajo, condenación de todo privilegio que no sea en beneficio del Estado, de todo sistema absorbente oligárquico, y de cualquier acto que atente o pueda perturbar el orden público y el imperio de la Constitución y de las leyes del Estado"38.

Nótese en dicha cita la evidente coincidencia con la noción del b i e n co $\mathrm{m}$ ú $\mathrm{n}$ y la necesidad de mantener el equilibrio de dos elementos aparentemente opuestos, como la fórmula necesaria para alcanzar el desarrollo de una sociedad.

En este contexto, los logros atribuibles a Cornejo a través de la instalación de la "Patria Nueva" serían la implementación de las asambleas y de los congresos, influenciados por el positivismo acerca de su concepción del Estado eficiente, del progreso social y del orden en que deben darse las relaciones entre los Estados, para lo cual, incluso, se justifica el autoritarismo en el gobierno.

Al mismo tiempo, a Cornejo también le corresponderá la defensa de las reformas constitucionales planteadas para afirmar el ingreso de Leguía al poder, llegando a sostener, desde el discurso de instalación de la Asamblea Nacional, que el Perú se emancipó sólo políticamente en 1821, pero no del p a r a s i t is mo bu ro c rát i c o y que la renovación parcial del Poder Legislativo no era expresión de la democracia, sino de la burocracia civil y había que desterrarla, para lo cual era necesaria la renovación total del Congreso, lo que justificaba el golpe del 4 de julio, pues la revolución era el único medio de lograrlo. Afirmaba, igualmente, que había que desterrar el centralismo, el caciquismo y la absorción del presupuesto de Lima ${ }^{39}$.

${ }^{37}$ Leguía, Augusto Bernardo, Discurso pronunciado en el Club de La Unión el 09 de febrero de 1919, citado por Ramos NúNEz, Carlos, Ley y justicia en el Oncenio de Leguía (Lima, 2015), p. 27. En igual sentido, ChaupIs TORREs, José, Patria y nación. Leguía durante el centenario de la Batalla de Ayacucho, en Investigaciones sociales, 19/34 (2015), p. 139.

${ }^{38}$ Miró Quesada Laos, Carlos, Autopsia de los partidos políticos (Lima, El Comercio, JulioDiciembre de 1919), p. 462.

${ }^{39}$ Guerra Martiniére, Margarita, cit. (n. 36), p. 247. Es preciso indicar que la línea crítica de Cornejo hacia lo que él consideraba como "parasitismo burocrático" no fue un argumento ensayado para satisfacer a Leguía, toda vez que tal postura ya había sido defendida con ocasión 
Otra interrogante surge de lo señalado: ¿cómo es que un personaje tan influyente como Cornejo no pudo concretar su modelo de administración de justicia penal basado en el sistema de jurado?

Para dar respuesta a dicha interrogante, es preciso analizar el enfoque que tenía Cornejo sobre el particular.

\section{Mariano H. Cornejo y el jurado}

Cornejo también recibió influencia de Emilio Castelar, en la medida de que el pensamiento de aquel se construye sobre la base de tres pilares: la adopción del sufragio universal, la instauración del jurado en el sistema penal y el perfeccionamiento institucional de la forma republicana de gobierno ${ }^{40}$.

En lo sucesivo nos centraremos únicamente en el segundo pilar: la preferencia de Cornejo por el jurado.

En pleno siglo XXI no es de recibo preguntarse en el Perú acerca de la posibilidad de instaurar el jurado en el sistema de justicia penal. Y es que, a pesar del proceso de reforma en el que nos encontramos actualmente, la academia todavía no se ha detenido a estudiar dicha posibilidad como una medida alternativa, sustitutiva o subsidiaria de los jueces técnicos. Hay un silencio sobre el particular.

Sin embargo, ello no fue así en los primeros años de vida republicana, tal y como lo demuestran las constituciones políticas del siglo XIX ${ }^{41}$ e, incluso, el propio Reglamento de Tribunales de 1858, en cuyo artículo 66 se prescribió que "Son atribuciones de estos jueces [técnicos]: conocer en primera instancia de las causas civiles del fuero común de su distrito judicial; de las capellanias laicales y sucesión á mayorazgos, y de las criminales en la forma actual, $m$ i e $n t r$ as se e s t a b le ce el juic io por jurados ${ }^{\text {s42 }}$. Tal opción legislativa del Reglamento de Tribunales, de hecho, sirvió de fundamento a Cornejo, para sostener que, en cualquier caso, los jueces técnicos solo detentaban una "[...] jurisdicción provisional" ${ }^{43}$. Provisional, mientras no se instaure definitivamente el j u r a d o. Pero, ¿en qué consiste el sistema de jurado concebido por Cornejo?

de su Conferencia sobre el jurado [véase antes, (n. 34), p. 56], a la vez que otros postulados ya habían sido expuestos casi veinticinco años atrás. CoRnejo, Ricardo H. cit. (n. 10), p. 10.

${ }^{40}$ Peralta, Víctor, cit. (n. 3), pp. 165-166. Este autor, además, da cuenta de lo señalado, a partir de las iniciativas adoptadas por Cornejo en su trayectoria política: "Cornejo desarrolló una temprana labor parlamentaria entre cuyas acciones destaca la presidencia de la comisión que en 1896 sancionó la ley electoral que regiría la alternancia en el poder hasta 1919. Asimismo, en 1914, fue uno de los ideólogos del abortado plan plebiscitario de Billinghurst, que de salir adelante hubiera supuesto la introducción en el país del régimen parlamentario. Finalmente, este personaje fue pieza clave en el asentamiento del régimen autoritario de Augusto B. Leguía al redactar, simultáneamente, las reformas constitucionales aprobadas por el plebiscito de agosto de 1919 y la Constitución de 1920”. Ibíd., p. 164.

${ }^{41}$ En tal sentido, puede apreciarse la Constitución Política de 1823, 1826, 1828, 1834 y 1839.

${ }^{42} \mathrm{El}$ espaciado es añadido.

${ }^{43}$ Cornejo, Mariano Hilario, Conferencia, cit. (n. 35), p. 56. 


\section{El proyecto de jurado en el pensamiento de Mariano H. Cornejo}

A decir de Cornejo, el jurado no es un sistema de justicia paralelo a la justicia penal promovida al interior de un sistema burocrático. Más bien, constituye una forma concreta en que el legislador ordinario operativiza el mandato constitucional de 1867, según el cual "[...] la justicia se administrará por los jueces y tribunales, en el modo y forma que la ley determina" ${ }^{4}$.

Por lo tanto, la regulación del jurado es de competencia del legislador ordinario, habida cuenta de que "Los jurados no expiden sentencias; expiden un veredicto que sirve de base á la sentencia; así como la declaración de un testigo ó el dictamen de un perito determina la sentencia. Son a u xilia res de los jueces" $(\mathrm{sic})^{45}$, en la misma medida de que los actuarios no requieren ser consagrados en la Constitución, a pesar de ser indispensables para la administración de la justicia ${ }^{46}$.

El contenido de la propuesta de Cornejo se encuentra en la noción de b i e n c o $\mathrm{m}$ ú $\mathrm{n}$. Esta comprende la necesidad de mantener un equilibrio entre el ejercicio del poder del propio Estado, ilimitado e irrestricto por naturaleza, frente a la defensa de la libertad propia del jurado, cuyo fundamento, a su vez, es de carácter moral. Y es que, a decir de Cornejo, el actual sistema adolece de un defecto estructural pendiente de ser solucionado, toda vez que "En el orden político ó judicial hemos copiado el mecanismo del poder, pero hemos olvidado el mecanismo del control; hemos traído las flores, los órganos por donde se consume la vida, y hemos olvidado las raíces, esas que en contacto con el suelo popular extraen los jugos nutritivos de la conciencia nacional" ${ }^{47}$.

La noción de b i e n c o m ú $\mathrm{n}$, por lo tanto, es una constante plasmada a lo largo del proceso penal previsto en el Proyecto del Código de Procedimientos en Materia Criminal formulado en 1916, dentro del cual la regulación del j u r a d o es una manifestación de tantas otras.

Así, a la vez de reconocer que los funcionarios se guían por el interés individual fundado en la razón, por lo que es obvio que estos mantengan su prerrogativa para dosificar la pena; el jurado, en opinión de Cornejo, constituye un elemento cohesionador y defensor de la moralidad de la comunidad. Por este motivo, este último debe ser el llamado a identificar qué hecho resultaría merecedor de pena.

Otro pasaje donde se advierte dicha dicotomía está en su concepción del procedimiento penal, al relegar la instrucción a un órgano altamente especializado, conocedor del Derecho y, por tanto, con claros intereses que busca preservar con ocasión del ejercicio de su función; pero que encuentra un evidente contrapeso al momento de juzgar, toda vez que el juicio o la crítica penal dependería exclusivamente de los pares legos llamados a equilibrar el ejercicio del poder. De ciudadanos que, al analizar un caso, han de tomar una decisión no sobre la base de intereses individuales, sino del interés colectivo que, en opinión de Cornejo,

\footnotetext{
${ }^{44}$ Cornejo, Mariano Hilario, Discurso defendiendo el libro Cuarto del Código que contiene el jurado, en AA.Vv., El jurado en el Perú pendiente de la resolución de la Cámara de Diputados (Lima, Imp. Torres Aguirre, 1920), p. 58.

${ }^{45}$ Ibíd., p. 59. El espaciado es añadido.

${ }^{46}$ Ibíd.

${ }^{47}$ Cornejo, Mariano Hilario, Conferencia, cit. (n. 35), p. 7.
} 
puede coadyuvar a disminuir el margen de falibilidad de los jueces técnicos en cuanto a la determinación de que el hecho pueda o no ser merecedora de pena.

Tres aspectos se puede destacar de lo señalado: primero, la decisión a adoptarse al término del juicio solo será aquella que se base en las pruebas sometidas al debate oral; segundo, dichas pruebas solo pueden ser aquellas que fueron obtenidas durante la instrucción o las ofrecidas excepcionalmente durante los actos preparatorios del juicio; $y$, tercero, el jurado solo tendrá competencia para juzgar las infracciones penadas con la muerte o penitenciaría, el infanticidio y demás crímenes contra la seguridad exterior del Estado, los crímenes de rebelión, sedición, motín, y asonada ${ }^{48}$. Es decir, cualquier delito especialmente grave.

Desde esta perspectiva, la concepción de sistema de justicia penal en Cornejo también se caracteriza por una justicia burocrática en ciertos aspectos, pero en otros aspectos ajena a todo vicio propio de la burocracia, al menos en aquellos aspectos donde, en su opinión, resulta preferible que el sistema deba fomentar la vigencia de la moralidad.

La implementación del jurado, en opinión de Cornejo, también va de la mano con su noción de descentralizar la administración de justicia ${ }^{49}$, a la vez de equilibrar las cuotas de poder existentes hasta aquella fecha en lo concerniente a la determinación del funcionario llamado a juzgar las causas penales ${ }^{50}$.

Así, frente a la influencia que tenía el poder ejecutivo en la designación de las altas autoridades del Poder Judicial, quienes, a su vez, tenían ciertas prerrogativas frente a los jueces de instancia; el proyecto de Cornejo suponía una mayor influencia de las partes en conflicto en relación a la designación de los miembros del jurado, a la vez que la propia conformación reflejaba una mayor intervención de la ciudadanía en lo concerniente al ejercicio del poder público durante el juicio oral, y, por ende, en la determinación de la verdad de los hechos.

Lo señalado se evidencia, a la luz del Proyecto del Código de Procedimiento en Materia Criminal, en la competencia definida para el jurado, cuya actuación se limitaba a la etapa de juicio oral, a la vez que el Ministerio Fiscal quedaba habilitado para formular la acusación.

${ }^{48}$ Gálvez, A.; Código de Procedimientos en Materia Criminal Promulgado por la Ley $n .{ }^{\circ}$ 4019 d 02 de enero de 1920 con citas, notas y concordancias (Lima, Imp. Sanmartí, 1920), p. 18.

${ }^{49} \mathrm{Al}$ respecto, Cornejo se pregunta “¿Creéis que no debe haber autonomía local, no debe haber autonomía de la conciencia local en materia de la penalidad? Pues, precisamente, no han nada más contrario á todos los principios que centralizar la jurisdicción penal en un solo tribunal. ¿Cómo en este país, en que nos hablan de descentralizar la administración, la política y los derechos de las provincias, no puede concederse la base elemental de toda descentralización: la descentralización de la conciencia moral, que es la base de toda autonomía? Sin ella no se puede tener autonomía administrativa ni política, no se puede tener municipio ni elegir un representante”. CoRnejo, Mariano Hilario, Conferencia, cit. (n. 35), p. 57.

${ }^{50} \mathrm{Al}$ respecto, Cornejo propone un complejo mecanismo de designación del jurado, cuya explicación merece un estudio más detenido. De este modo, al respecto nos limitamos a indicar que la propuesta de Cornejo en este extremo apuntaba a generar mayor participación de las partes comprometidas con el sistema de administración de justicia penal, de modo que el Ejecutivo veía reducida su cuota de poder, en aras de legitimar la intervención del acusado, del promotor fiscal y hasta del propio Poder Judicial. 
Dicho diseño permitió distinguir el jurado concebido por Cornejo del ya existente jurado de los juicios por delitos de imprenta, cuya inspiración fue de origen inglés. Y es que, mientras en la propuesta de Cornejo el jurado es entendido como un auxiliar del juez técnico, en tanto que es el autorizado para realizar el juicio de hecho; el procedimiento previsto en la Ley de delitos de imprenta comprende dos jurados: uno con competencia para pronunciarse sobre el fondo del asunto y otro que actúa como órgano de acusación" ${ }^{51}$, lo que "[...] es una aberración, porque es imposible que antes de que la instrucción esté formada, haya ningún ciudadano con bastante crueldad para condenar á una persona á quien se acusa, sin saber si es ó no realmente delincuente" $(\mathrm{sic})^{52}$.

En cuanto a su organización, el proyecto estipuló que el jurado sea elegido a partir de una terna de 100 a 500 ciudadanos conformada a iniciativa de los alcaldes municipales (arts. 373-374 Proyecto CPMC), de los cuales, luego del escrutinio de la sociedad civil y las recusaciones promovidas por las partes (Ministerio Fiscal y acusado) solo 12 participaban finalmente en un juicio oral en concreto. La inconcurrencia de los ciudadanos convocados también podía acarrear multas o penas de prisión.

El proyecto contempló, además, que las personas con aptitud para conformar un jurado debían ser ciudadanos peruanos en el ejercicio libre de sus derechos civiles y políticos, hayan cumplido 25 años y no hayan superado los 70 , a la vez de que sea un sujeto contribuyente, u ostente o haya ostentado algún cargo público, entre otros aspectos (art. 377 Proyecto CPMC). Los extranjeros, los d o m é s t i c o s y las mujeres no estaban comprendidos dentro de dicho universo.

Otro aspecto que se desprende de este modelo radica en el complejo procedimiento establecido en aras de observar la oralidad. Y es que, si bien por un lado el legislador ha vedado toda posibilidad de leer las declaraciones previas bajo sanción de nulidad (art. 222 CPMC), salvo situaciones excepcionales (art. 224 CPMC); pareciera que la incorporación de dichos testigos al juicio oral está condicionada a la presentación previa de un pliego interrogatorio, lo que permite advertir que, en cualquier caso, la práctica de la prueba personal no se produce a través de las partes, sino del juez o del jurado encargado de leer dicho pliego. El proyecto no fue suficientemente claro en este aspecto.

${ }^{51}$ Ramos Núñez, Carlos, Justicia profana. El jurado de imprenta en el Perú (Lima, Fondo Editorial Pucp, 2018), Edición Kindle; Miró Quesada LaOs, Carlos, Autopsia de los partidos politicos (Lima, El Comercio, Julio-Diciembre de 1919), p. 462.

${ }^{52}$ Connejo, Mariano Hilario, Discurso, cit. (n. 45), p. 61. Es preciso indicar que la crítica al modelo inglés del jurado provino de diversas fuentes, por lo que su derogatoria no se debe a la influencia concreta del positivismo criminológico de la época. Abundan en contra de tal institución, quizás, mayores razones de carácter práctico, habida cuenta del elevado nivel de impunidad advertido en la época. A tal efecto, GutiérRez Ballón indica que, por ejemplo, entre 1889 y 1910 se "...presentaron un total de 155 denuncias: 138 por particulares, 16 por agente fiscal y 1 por el promotor fiscal eclesiástico. De estas, 44 fueron declaradas para que hubiera formación de causa; 15, en contra; y, en 96 casos, el jurado no llegó a reunirse”. En RAmos NúNEZZ, Justicia profana, cit. (n. 52), Edición Kindle 


\section{2. ¿Por qué razón no se llegó a concretar el jurado a lo largo del siglo XIX?}

Esta interrogante puede responderse desde dos perspectivas. Desde el primero, se advierte que la no implementación del sistema de jurado se debió a que dicha propuesta no generaba ningún crédito político a quien lo promueva ni a los propios burócratas.

Y es que, conforme lo reconoció Cornejo, "[...] en el jurado no se gana nada, ni sueldo ni beneficio; porque no se pueden hacer servicios á nadie, ni ejercitar venganzas; en una palabra, porque no existe ventaja ninguna. Si [del] jurado se derivara la más pequeña ventaja personal, las ventajas que se derivan de cualquier corporación, existiría el jurado desde hace mucho tiempo, existirían jurados en todos los departamentos, en todas las provincias, en todos los distritos. Nadie los podría, no digo suprimir, ni disminuir siquiera" ${ }^{33}$.

Tal circunstancia podría haber supuesto "[...] Un temor aristocrático que paralizaba cualquier iniciativa legislativa a lo largo del siglo" ${ }^{4}$, situación que, en efecto, coincidió con las voces críticas provenientes del Decano del Colegio de Abogados de la época Manuel Vicente Villarán y, evidentemente, de la propia burocracia ocupada, principalmente, por militantes o simpatizantes del Partido Civil.

Desde otra perspectiva, la implementación del jurado puede que haya sido observada por Augusto B. Leguía, desde el momento en que su implementación importaba una evidente d e m o c r a t i z a c ión del ejercicio del poder en lo concerniente a la administración de justicia penal respecto de los delitos más graves $-\mathrm{y}$, hasta cierto punto, con marcada influencia política- ${ }^{55}$.

$\mathrm{Y}$ es que continuar con este proyecto habría supuesto ceder la injerencia del Ejecutivo en el Poder Judicial a favor de ciudadanos ajenos a su gobierno o manifiestamente opuestos a este.

Con todo ello, lo cierto es que la década del 1920 significó, por un lado, la concreción ideológica de Cornejo en lo legislativo, tanto a nivel del constituyente como en lo ordinario, si bien de manera parcial; y, por otro lado, la continuación de su trayectoria como diplomático, al ser designado por el gobierno como representante extraordinario del Perú en Francia. A decir de Peralta ${ }^{56}$, tal situación significaría el interés del gobierno de mantener alejado a Cornejo ${ }^{57}$, situación que se mantuvo hasta que los partidarios de Leguía requirieron de su apoyo ideológico para preparar la segunda reelección presidencial en 1928 y la conmemoración de los veinticinco años de vida política de Augusto B. Leguía.

Fue en estas circunstancias que Cornejo pronunció su discurso "Exégesis de la

\footnotetext{
${ }^{53}$ Cornejo, Mariano Hilario, Conferencia, cit. (n. 35), p. 56.

${ }^{54}$ Ramos NúNez, Carlos, El jurado criminal en pugna. Un debate con resonancias en América Latina, en Themis, 73 (2018), p. 84.

${ }^{55}$ Mariano H. Cornejo fue un académico con bastante tacto político, por lo que, evidentemente, tal afirmación no la sostuvo expresamente, sino que la encubrió a través de ejemplos o paráfrasis cuyo mensaje, evidentemente, apuntaba a cuestionar el sistema judicial vigente en su época. Cornejo, Mariano Hilario, Conferencia, cit. (n. 35), p. 48.

${ }^{56}$ Peralta, Víctor, cit. (n. 3), p. 187.

${ }^{57} \mathrm{La}$ decisión del gobierno de mantener alejados a sus eventuales opositores políticos o pensadores cuyo discurso puede ser contrario a sus intereses fue una práctica generalizada, que no solo se advierte en relación a Cornejo.
} 
Patria Nueva", cuyo contenido, de hecho, reveló una crítica respecto de las obras del gobierno. Y es que, a la vez de destacar la importancia del significado moral de la "Patria Nueva" -en cuanto movimiento ideológico dentro de la evolución de la política en el Perú-, prefirió mantener absoluto silencio respecto de las obras materiales que Leguía promovió durante los primeros ocho años de gobierno ${ }^{58}$.

\section{BALANCE Y PERSPECTIVA. UN ENSAYO A MODO DE CONCLUSIÓN}

El presente ensayo biográfico de Mariano H. Cornejo permite sostener que su estudio no necesariamente debe reducirse a una determinada escuela -el positivismo-, si bien esta fue determinante en la evolución de su pensamiento. Más aún cuando la influencia de dicha corriente sociológica no se limitó a su quehacer en la academia, sino también en el ámbito político.

Otra conclusión consiste en que el imaginario político de Cornejo, influenciado por su concepción teórica del b i e n c o m ú n, no se reduce a una lógica partidista. Asumir ello importaría sostener que Cornejo se guío por los intereses individuales que él mismo criticaba, cuando estos aparecen en desproporción al orden que se debe preservar.

En el ámbito procesal penal, si bien resulta que su proyecto principal -la implementación del jurado en la justicia penal- no fue aprobado ${ }^{59}$, lo cierto es que muchos de sus ideales sí quedaron plasmados en el Código de Procedimientos en Materia Criminal de 1920.

Un ejemplo evidente es que la noción de e qu i libri o se plasmaría en el diseño propio de la estructura procedimental del proceso penal, con dos etapas estructuralmente opuestas, pero funcionalmente complementarias: la instrucción o sumario y el plenario, ambos sustanciados por órganos distintos, con atribuciones distintas, pero, hasta cierto punto, complementarias.

De este modo, el mérito que corresponde reconocer a Cornejo radica en que su labor legislativa marcó un antes y un después en lo concerniente al proceso penal, con la consecuente derogatoria de los j u e ce s d el c r i m e n que, a la usanza del Derecho colonial, se habían mantenido a lo largo de la primera centuria de vida republicana en el Perú; y que, lamentablemente, volvería a tener vigencia con la implementación de los procesos penales sumarios (D. Leg. n. ${ }^{\circ}$ 124) desde el 12 de junio de 1981 hasta nuestros días.

A tal efecto, Cornejo explicó que "El nuevo Código suprime el sumario inquisitorial, la instrucción secreta basada en la denuncia, el plenario y todo un

${ }^{58}$ Ibíd.

${ }^{59}$ Más allá del debate académico producido en la época en torno a la viabilidad de incorporar el jurado en la justicia penal, lo cierto es que su no aprobación se debió, principalmente, a razones políticas: (i) el carácter pragmático de Augusto B. Leguía, cuyo régimen se favoreció del discurso de Cornejo para confrontar ideológicamente al Partido Civil que gobernó durante las dos primeras décadas del siglo XX (Peralta, Víctor, cit. (n. 2), p. 186); y (ii) la decisión del Ejecutivo de mantener su influencia directa en el sistema de designación judicial consagrado en la Constitución de 1920 -invariable en este extremo desde la Constitución de 1860- que, evidentemente, era contrario al sistema juradista. RAMOs NúNEZ, Carlos, Ley y justicia, cit. (n. 38), p. 19. 
sistema que se exhibe objetivamente en un expediente de fojas grasientas, con letra ininteligible y redacción torpe que muestra en cada renglón la mistificación; en las declaraciones la suplantación; en los peritajes la mala fe y la mentira; el expediente es algo que ensucia las manos y envilece las conciencias" ${ }^{60}$.

\section{BiBLIOGRAFÍA}

Aguirre, Carlos, Delito, raza y cultura: El desarrollo de la criminología en el Perú (18901930), en Diálogos en Historia, 2 (2000), pp. 179-206.

Basadre Grohmann, Jorge, Perú: Problema y posibilidad (Lima, Librería Francesa Científica y Casa Editorial E. Rosay, 1931).

Chaupis Torres, José, Patria y nación. Leguía durante el centenario de la Batalla de Ayacucho, en Investigaciones sociales, 19/34 (2015), pp. 131-141.

Contreras, Carlos, \& Zuloaga, Marina, Historia minima del Perú (Madrid, Turner Publicaciones, 2019).

Cornejo, Mariano Hilario, Conferencia sobre el Jurado sustentada por el Presidente de la Comisión Reformadora de los Códigos Penales, Dr. D. Mariano H. Cornejo, el domingo 6 de agosto de 1916, en el Teatro Excélsior (Lima, Imprenta del Estado-Núñez, 1916).

-Discurso defendiendo el libro Cuarto del Código que contiene el jurado, en AA.Vv., El jurado en el Perú pendiente de la resolución de la Cámara de Diputados (Lima, Imp. Torres Aguirre, 1920), pp. 54-96.

-Discurso pronunciado el 13 de agosto de 1901 en defensa de los fueros del parlamento al sostener el voto de censura al gabinete Almenara, en CoRnejo, Ricardo H., Mariano H. Cornejo. Discursos Escogidos (Lima, Editorial Jurídica, 1974).

Cornejo, Ricardo H., Datos biográficos y remembranzas, en Cornejo, Ricardo H., Mariano H. Cornejo. Discursos escogidos y datos biográficos (Lima, Editorial Jurídica SA, 1974), pp. 9-46.

Denegri Cornejo, Hugo, Mariano H. Cornejo, el hombre y su obra en el centenario de su nacimiento. Disertación en el Colegio de Abogados de Lima (Lima, 1966).

Gálvez, A.; Código de Procedimientos en Materia Criminal Promulgado por la Ley $n .{ }^{\circ}$ 4019 de 02 de enero de 1920 con citas, notas y concordancias (Lima, Imp. Sanmartí, 1920).

Guerra Martiniére, Margarita, La "Patria nueva" de Leguía, en Boletín del Instituto Riva-Agüero, 16 (1989), pp. 245-252.

Mejía Navarrete, Julio, El desarrollo de la sociología en el Perú. Notas introductorias, en Sociologías, 14/7 (Porto Alegre, 2005), pp. 302-309.

${ }^{60}$ Denegri Cornejo, Hugo, Mariano H. Cornejo, el hombre y su obra en el centenario de su nacimiento. Disertación en el Colegio de Abogados de Lima (Lima, 1966), p. 56.

En igual sentido, el presidente de la Corte Suprema, Anselmo Barreto, sostiene, mediante una Circular de la Corte Suprema de fecha 04 de febrero de 1920, que "Los juicios por delitos no exceptuados de la intervención del Ministerio fiscal, constan de sumario y plenario, según la ley actualmente en vigor, y el agraviado tiene en todo tiempo el derecho de querellarse. Estos dos ejes del enjuiciamiento desaparecen en la nueva ley: los jueces del crimen no sentenciarán ya esas causas, pues, son meros jueces de instrucción, y concluida ésta, se abre el juicio oral ante la sala de la Corte Superior constituida en Tribunal correccional; y contra la sentencia que éste pronuncie, hay recurso de nulidad para ante la Corte Suprema”. 
Miró Quesada Laos, Carlos, Autopsia de los partidos políticos (Lima, Ediciones Páginas Peruanas, 1961).

-Autopsia de los partidos políticos (Lima, El Comercio, Julio-Diciembre de 1919).

Peralta, Víctor. Un cientifico en la política peruana. Mariano H. Cornejo, la república aristocrática y la patria nueva, 1895-1920, en Revista Complutense de Historia de América, 27(2001), pp. 163-189.

Quiroz, Alfonso W., Historia de la corrupción en el Perú (Lima, Instituto de Estudios Peruanos, 2013).

Ramos NúNEz, Carlos, El jurado criminal en pugna. Un debate con resonancias en América Latina, en Themis, 73 (2018), pp. 83-94.

-Justicia profana. El jurado de imprenta en el Perú (Lima, Fondo Editorial PucP), 2018. Edición Kindle.

-Ley y justicia en el Oncenio de Leguía (Lima, 2015).

Ramos Rau, Demetrio, Hildebrando Castro Pozo, en Pueblo Continente, 17/1 (2006), pp. 97-102.

Rochabrún Silva, Gillermo, Sociología y pensamiento social en el Perú 1896-1970. Encuentros y desencuentros (Tesis para optar el Grado Académico de Magister en Sociología, Lima, 1998).

Sociedad Central de Emigración Alemana, Emigración alemana con destino al Perú año de 1851 (Londres, T. E. Newell S. Cloak Lane, Cheapsdk, 1855).

Sulmont, Denis, La sociología francesa en el Perú, en Bulletin de l'Institut Français d'Études Andines, 36/1 (2007), pp. 85-92. 